\title{
The NEUST-SIC Research Hub, A Compendium of Researches
}

\section{Emmanuel Carlos Navarro}

College of Information and Communications Technology, Nueva Ecija University of Science and Technology, San Isidro, Nueva Ecija, Philippines.

\begin{abstract}
This study aimed to design and develop a system entitled The NEUST-SIC Research Hub - a compendium of researches that aimed to integrate the researches conducted by members of the faculty, staff and selected students into one repository hub.

The primary goal of this study was to develop a research repository. This repository will be used to collect, manage and store the researches. This system records all the electronic research outputs, research publications, and working research papers handled by the University Research Services Unit.

Other features of the developed system are the following: input and list of campus researches, user accounts for the researchers, profiling of the researchers, a tracking system for working research papers, announcements about the University Research Service Unit activities and an online access web page that displays the published and conducted research. The management of the system will be the sole responsibility of the Research Services Unit department in the coordination of the Management of Information System department. They will manage the use of the system. The maintenance is reserved to the research proponent.

The system was evaluated by university research reviewers and selected IT experts who assessed the system's functionality, efficiency, validity, reliability, maintainability, and portability based on the ISO/IEC 25010:2011 software development standards.
\end{abstract}

Keywords-Compendium, Report Analytics, Repository, Research Hub, Tracking-system, Work-Flow.

\section{INTRODUCTION}

The new generation of modern Information Technology permeates in every sector of the community. It has become a tool used for providing faster and easier service (Diaz, 2018). These technologies are used by the experts, contributors, designers, developers, formulators, inventors, originators who belong to private industry, government and in the Academe.

With the use of several tools of technology that control everything, the hardships we experience in exploring and communicating to get the information will now be lessened. Now, with just a matter of clicks to be informed and updated (Navarro and Salas, 2020) in order to know the latest happenings in the mainstream using different platforms that offer to keep us within reach. Despite the all-powerful tools introduced to make the work easier, there are still certain operations such as data recording that are carried out manually. Even large companies are adamant in fully utilizing technologies because they feel that their old ways are still effective. There are also some organizations that are bound in traditions where it is the foundation of their belief and success in business. In most government agencies, recording of data is still done manually. In colleges and universities, the methods in collecting data are prepared using pen and paper. Record books are used to keep the details of information, and these books are filed in cabinets. In the Universities, this practice still exists. Researches, for instance, are still being managed the traditional way. They are still filed and stored manually.

People make research everywhere. Even in the business sector, they conducted researches to gather facts that will help them improve the quality of their services and be competitive. In the health sector, they conduct researches to improve the delivery of services. Government agencies also do research such as Philippine Statistics Authority (PSA, 2019) in charge in collecting, compiling, classifying, and producing general-purpose of statistics, the National Economic and Development Authority (NEDA) responsible in the planning of economic development, to 
name a few. With a huge data collection tool, it increases the level of research efficiency where it helps to speed up the process and save time as well as the resources. For instance, in colleges and universities where research is a requirement, they must have a management tool to protect, maintain and record their researches.

Hence, considering that the San Isidro Campus and the university as a whole is promoting a research culture among faculty, staff and students a tool that is fast and is reliable that will store researches electronically is highly needed. According to (Bethune, et al, 2017) institutions must carefully maintain and update records of their scientific publications. In this way, knowledge resource of the university will be preserved and readily available for those who wish to utilize its output. The Research Services Unit, as the prime source and controller of the researches, will have an online access with high data security and integrity. This developed system will provide an avenue for future researches because past researches will be readily available. The Nueva Ecija University of Science and Technology - San Isidro Campus Research Hub will provide fast access to the list of university research archives.

\section{OBJECTIVES}

The primary objective of this study was to develop the NEUST-SIC Research Hub for faculty, staff, and student that will manage and provide fast accurate open access compendium of researches.

The specific objectives were the following: (1) to provide record management of researches; (2) to promote the research services unit activities; (3) to provide open access to researches conducted by faculty, staff and students; (4) to track whether the research is published or is implemented by technology transfer to target beneficiary or community, or still ongoing; (5) to connect the author/s published researches to their respective online publication; (6) to archive researches; (7) to produce report analytics of the researches; and (8) to generate research summary report.

\section{METHODOLOGY}

Developmental research design was utilized in this study. This research study focuses on progressive changes. According to (Kowalzyk, 2014), it aims to gradually improve the policies, ideas, concepts, methods, and materials or instruments. Furthermore, according to (Richey, 1994) to meet the specific requirement to measure the consistency and efficiency of the system, it must be done in a systematic study of designing, developing, and evaluating instructional programs, processes, and products.

\section{A. Research Design}

The development of the system followed the agile software development process. According to (kiss, 2016) the aim of the agile process was dividing the project into smaller pieces instead of building one enormous project. In addition to that, (Reeve, 2012) stated that Agile software development allows the web developers to start with the basic specification and general direction, then work through the project iterations. This procedure, based on iterative development called sprints. In each sprint cycle, there was iterative course to take such as planning, analyzing, designing, developing, testing, and evaluating. This cycle were repeatedly performed until the desired output was met.

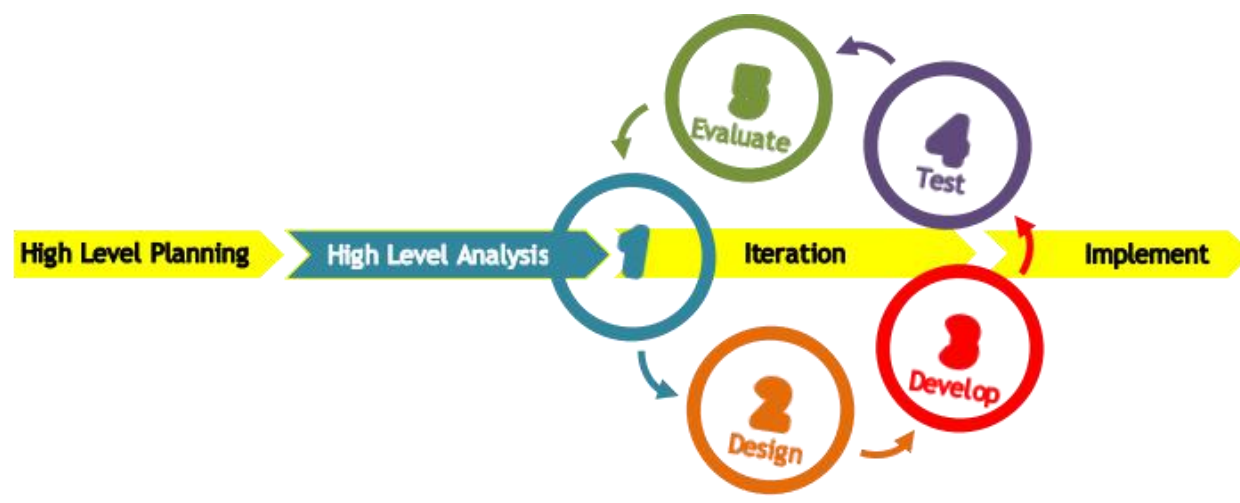

Fig. 1: Agile Software Development Process

The development period of the NEUST-SIC Research Hub started from the high level of planning. That phase included a number of activities such as gathering data, conducting interviews, and formulating measurable strategic goals (Barker, 2019). These activities produced inputs that were subjected for evaluation. In addition to 
that, (Lee, n.d.) in his blog article at ngo.diona.com stated that power of good data analysis based on good data collection can do amazing things. Further, he urged that good data analysis needs good data collection.

The next step was analyzing the gathered requirements. Book authors (Stimson, Stough, and Roberts, 2006) stated that analysis plays a vital role in research. It carefully studies the problem, breaking the process into small pieces to understand and come up with the essential details needed in the development of the system.

In conceptualizing the design of the system a research paradigm was illustrated based on the Input-Process-
Output (IPO) model. A Gantt Chart table was prepared to monitor the schedule of development. Several modules of software engineering were observed in defining activities to go through the development, such as integration of context diagram which identifies the roles of the users, a data flow diagram that explains the sequence of action process that goes around the system. A use-case diagram was utilized to show the interaction of the users with the system. According to an article from Smartdraw.com entitled "Use Case Diagram" (n.d.), is a set of actions, services, and functions that the system demands to deliver. Moreover, the entity-relationship diagram that shows the relations of database tables.

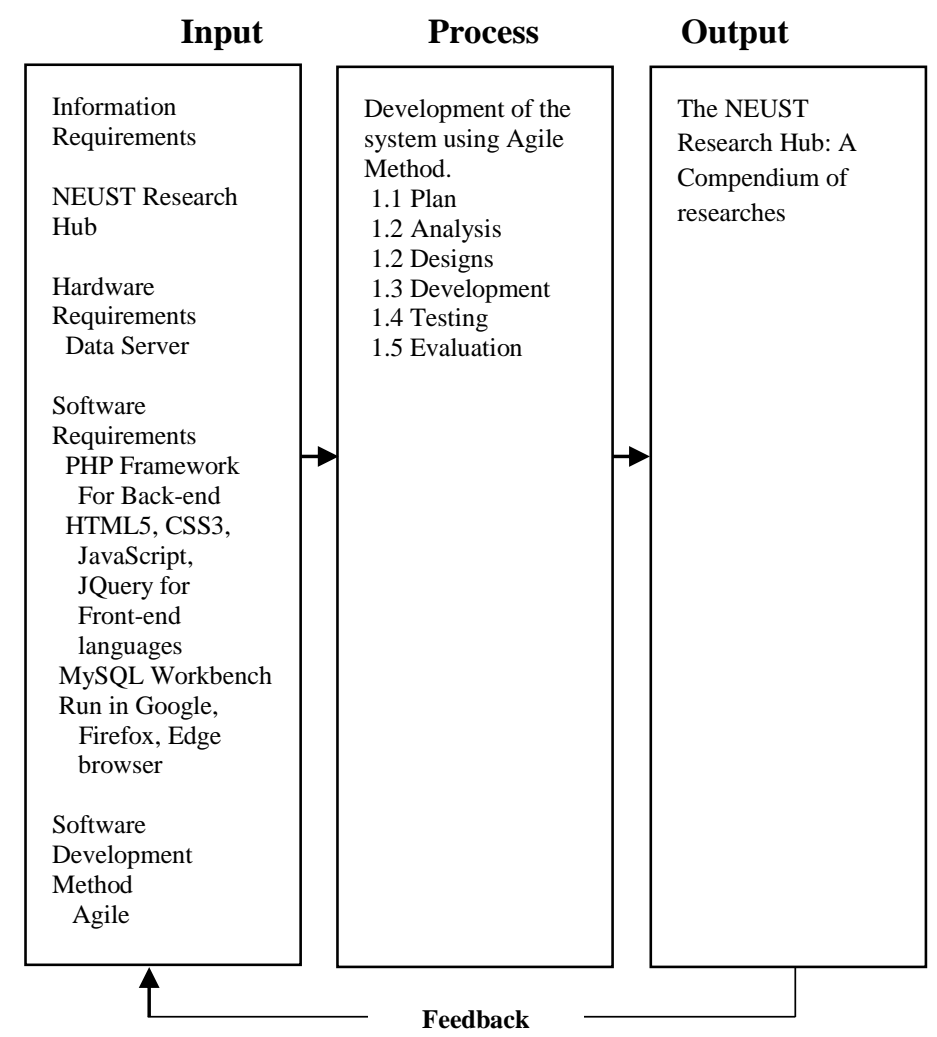

Fig. 2: Research Paradigm

This framework describes the inputs, processes, and outputs of the developed system. With this design, it shows how the required information were collected and managed, and what data for intended users were needed to gather.

The input box lists the information that served as basis for the development of the system. Requirements gathering and analysis were conducted to the research department of the San Isidro Campus, it observed the procedures of how they arrange and achieve the researches administered by the faculty, staff, and student of the campus. All of the inputs were validated by observation were incorporated into the development of the NEUST-SIC Research Hub system. The minimum hardware specifications includes at least quad-core $2 \mathrm{Ghz}$ or higher to perform smooth, efficient, and shared data faster. The software requirements included the PHP used for backend, which is a free, open-source PHP framework for a web application. Alongside with the HTML5, CSS3, JavaScript, and JQuery languages were used for front-end, HTML was for the layout and structure of the web, CSS tool for styling, JavaScript for rendering dynamic environment behavior, and application of predefined JavaScript library called JQuery, which utilized to add more animations to the data. For database management, MySQL Workbench, a unified 
visual tool used, provided data modeling, SQL development, and comprehensive administration tools for server configuration, user administration, and backup.

The process box shows the stages undergone during the conduct of the study.

The output box was the target developed NEUST-SIC Research Hub: A compendium of researches. And feedbacks were collected and they were incorporated into the continuous development of the system.
In an article from Projectmanager.com, according to (Bridges, 2019 ) workflow was defined as the definition, execution, and automation of business processes. In the above diagram, it presents the technical process of NEUST-SIC Research Hub, and this details the operation inside the system. In this way, the course of information moves organizes and executes its intended purpose efficiently.

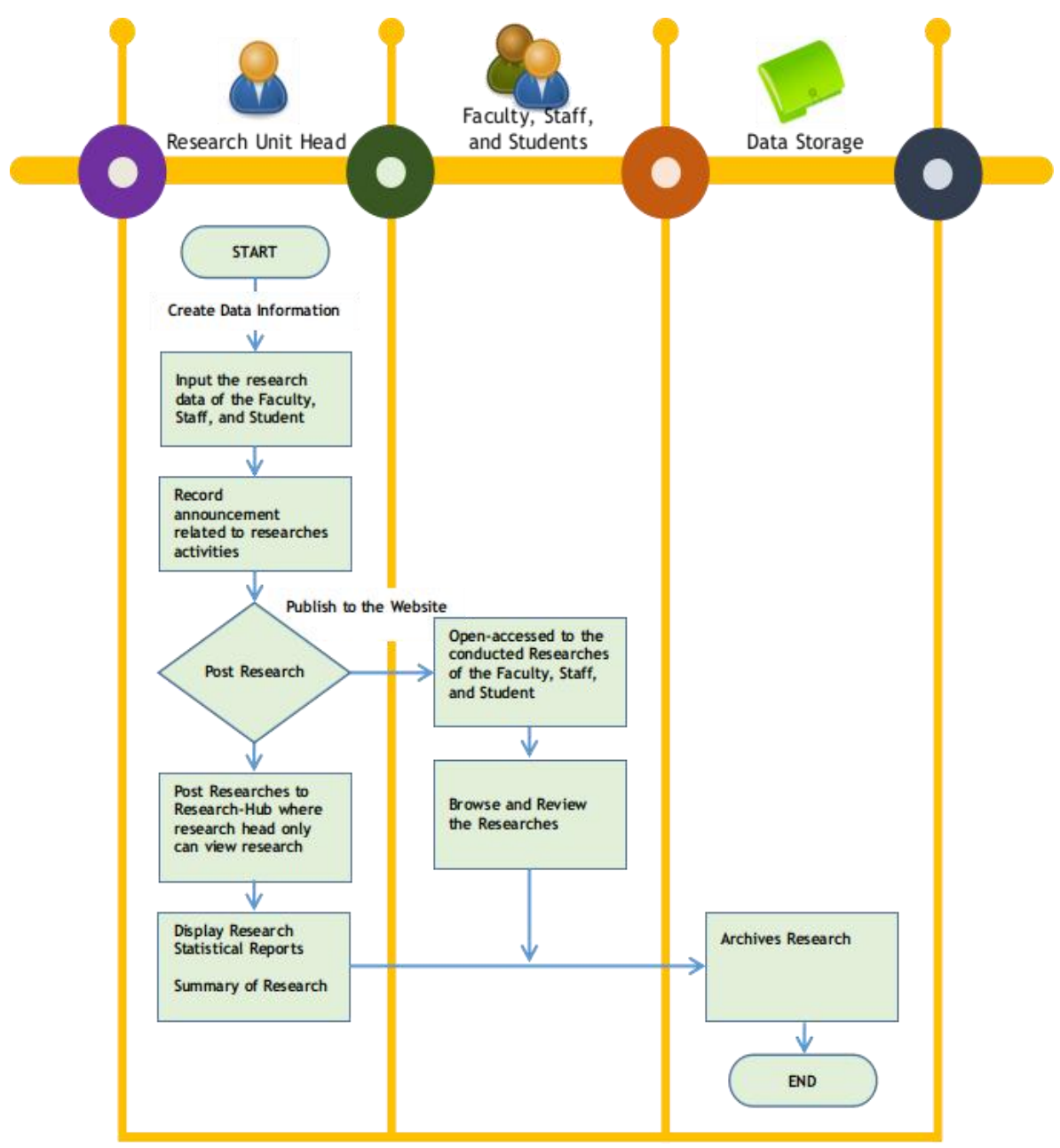

Fig. 3: Workflow of NEUST-SIC Research Hub

During the developing stage, the back end and front end was developed. These two were integrated with the use of an Application Program Interface (API). The system was developed using open-sources programming languages plus some support plugin component that adds a specific feature easy for handling.

LAMP (Linux, Apache2, MySQL, and PHP) was used as a localhost webserver to run and test the developed NEUSTSIC Research-Hub. In an article from Digitalocean.com by (Heidi, 2020) she explains that "LAMP" was a stack group of open-source software that is typically installed together to facilitate the server in hosting dynamic websites and web apps that written in PHP. For this particular development, the version used in the coding process was PHP 7.2, alongside with HTML5, CSS3, JavaScript, JQuery in building various functions of the web application in setting file structures, intensifying the aesthetics side of webpages. Bootstrap 4 was also used in designing website responsiveness together with Material Icons in providing the graphical icon. In defining database structure MySQL Workbench was employed for simple management of database tables, and lastly, the code was written in text editor Sublime Text3. 
A series of tests were conducted with end users to assess the system's functionality and to check for possible loopholes. Feedback were collected and were treated for further system improvement.

\section{B. Results}

The developed system was evaluated meeting the functionalities needed for a Research hub repository. Users were found satisfied upon testing it.

The Research Hub system was developed to keep all the researches conducted by the NEUST-SIC faculty, staff, and students in one repository. The developed system provides a dedicated account for the research head who will maintain and manage the system. It also features the creation of department, course, research field of specialization, and research department activities. For the researcher's side, the research hub was designed as an open-access journal type where the visitors are allowed to browse and review the contribution of the NEUST-SIC studies.

One of the features of the developed system directly connects to the published research articles to the address of the website of the researcher journal of publications. It also highlights the status of the researcher study to track if it was published, presented, completed, and still on-going development.

Archiving of the research was created, the researches are cached in the storage section of the system to preserve the studies for future reference. Only the administrator can access the research archives. The system is capable of generating a report per faculty and student researches, the same with summary per category represented in a statistical chart.

The figure below shows the structure of the NEUST-SIC Research Hub. It details the recording of researches from creation up to posting to the university website wherein this is the sole responsibility of the research unit head. The faculty, staff, and students may access the published researches. keep abreast of the latest happening about research activities of the university particularly the San Isidro Campus. The guest's accounts who visited the website are free to browse the studies. They can also view the statistics per category, and lastly, the researches stored in one repository that solely managed by the research head unit.

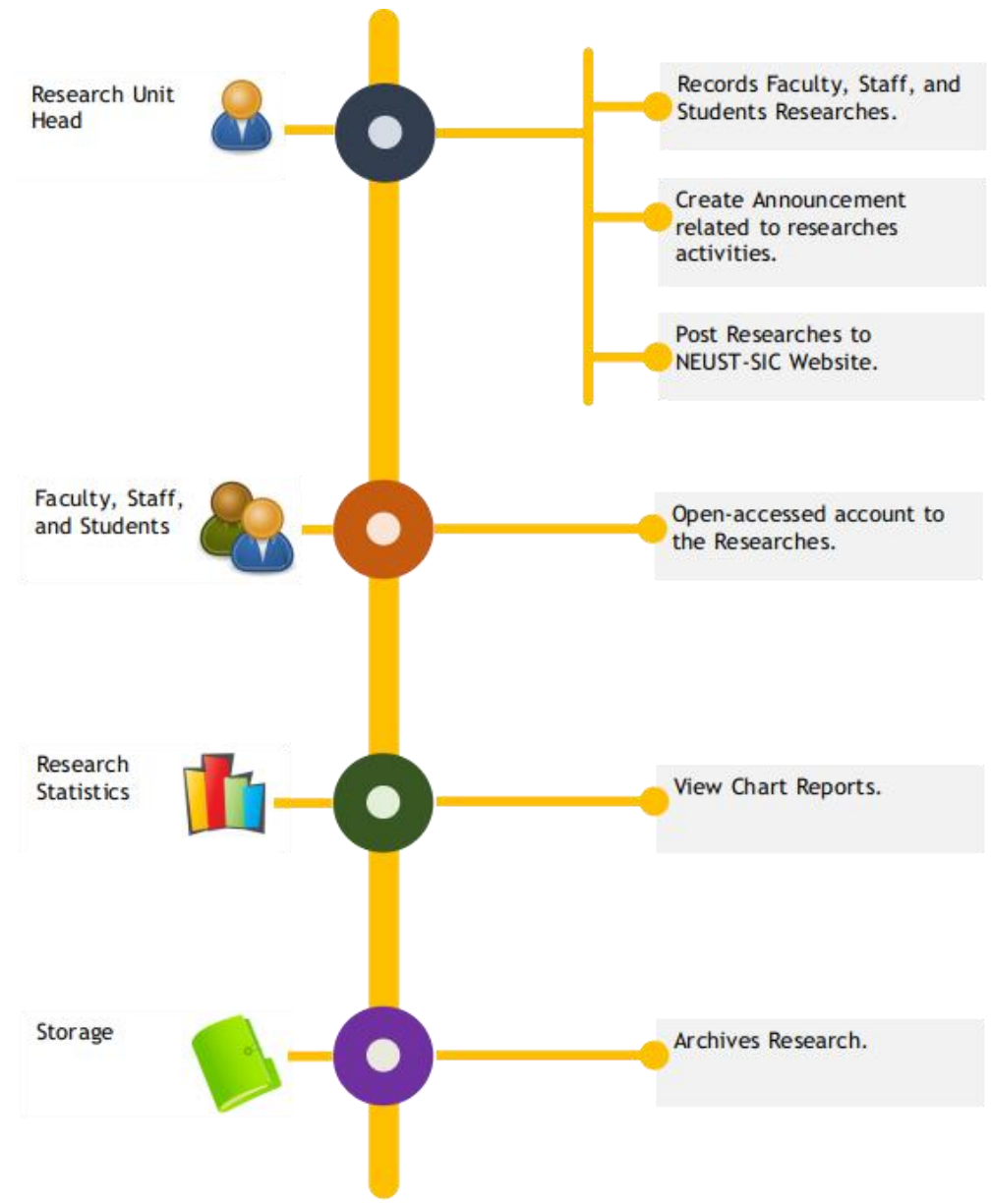

Fig. 4: Structure of NEUST-SIC Research Hub 
The figure shown below was the captured screenshot of one of the modules of the NEUST-SIC Research Hub system. It displays the statistical reports of the researches. It is capable of filtering based on the the status as per 'ongoing study, presented through in-house review, or completed researches. Pie, bar, and curve charts were used for simple presentation. The chart projection was the results of research for the past five years, according to the number of studies conducted, its category, and count of research per year.

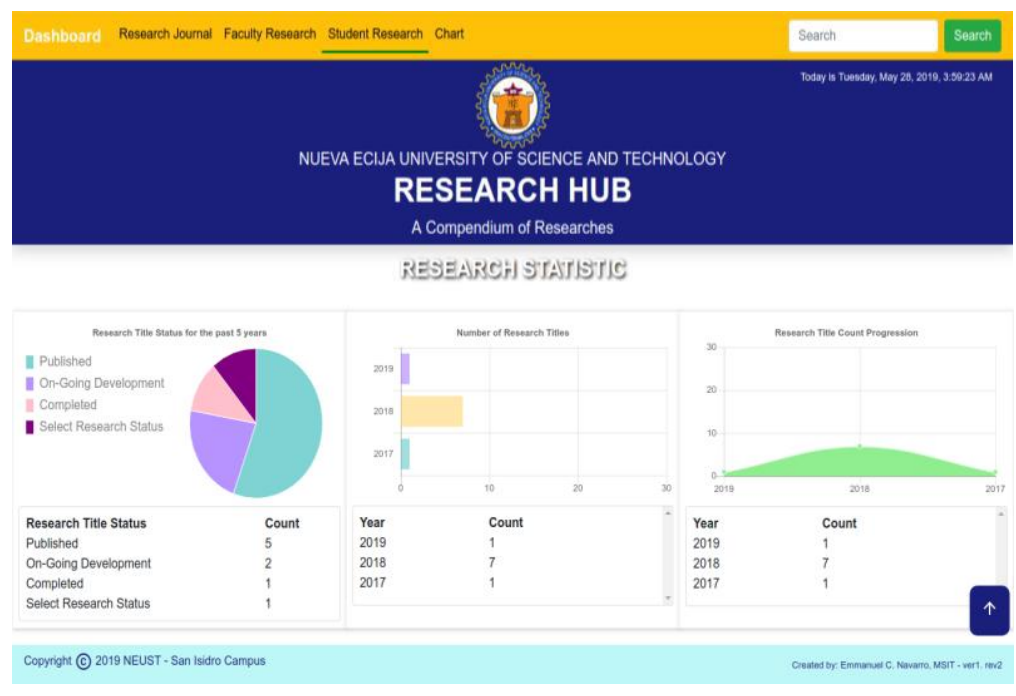

Fig. 5: Statistical report of researches

\section{Discussion}

The NEUST-SIC Research Hub: A compendium of researches was presented during the "In-house review of completed research" one of the research activities of the university. The panel examined carefully the developed system in terms of functionality and usability. They suggested the developed system as the repository of university researchers be utilized in the University. The developed research hub was evaluated by the selected IT experts who assessed system functionality, efficiency, validity, reliability, maintainability, and portability based on the software development standards. According to the articles from iso.org (ISO/IEC 25010:2011, 2011) this standard was defined as a system model applicable to the complete human-computer system composed of five characteristics that relate the outcome of interaction when a product is used in a particular context of use. The results of the evaluation and feedbacks of the evaluators were collected and incorporated into the further development of NEUST-SIC Research Hub.

\section{CONCLUSION AND RECOMMENDATION}

Based on the finding of the study, the NEUST-SIC Research Hub was developed. In the current setting of the university, the proponent found out that there was no existing automated system that stores the researches of San
Isidro Campus. These preceding conclusions, a centralized repository that have been created as an openaccess compendium of researches which manages studies in a secure database system will help the research department in collecting the researches. This system provides an opportunity for future researches to use the available researches as references for their study. Redundancy of researches conducted in the University may now be avoided

The following recommendations are hereby given; for full implementation of the system, the said system be also utilized in other departments, consider the said system implementation as a benchmark in aligning the inputs and processes of the NEUST research system.

\section{REFERENCES}

[1] Barker, Lesley. (2020, May 14). Definition of Development Planning. careertrend.com. Retrieved from https://careertrend.com/about-5095844-definitiondevelopment-planning.html

[2] Bethune, J., Kraemer, L., Thomsen, I. et al. LitDB - Keeping Track of Research Papers From Your Institute Made Simple. Source Code Biol Med 12, 5 (2017). Retrieved from https://doi.org/10.1186/s13029-017-0065-2 on November 20, 2018. 
[3] Bridges, Jennifer. (2019, December 6). 3 Steps to Designing a Powerful Project work-flow- ProjectManager.com. Retrieved from

https://www.projectmanager.com/training/define-workflowprocess.

[4] Devin Kowalczyk, What is Developmental Research? Definition, Purpose \& Methods. (2014, January 23). Retrieved from https://study.com/academy/lesson/what-isdevelopmental-research-definition-purpose-methods.html.

[5] Diaz, Rowell A. (2018). Quality of Service of Selected Courier Service Company in Cabanatuan City: It's Implication to Customer Satisfaction. International Journal of Management Sciences and Business Research, Nov-2018 ISSN (2226-8235) Vol-7, Issue 11, 162-168.

[6] Doctor, Dan. (2017) Importance of Data Collection And Management For An Organization. Retrieved from http://blog.sollers.edu/data-science/importance-of-datacollection-and-management-for-an-organization, dated June 12, 2017 12:13:26 PM.

[7] E.W.T. Ngai,Li Xiu,D.C.K. Chau, Application of data mining techniques in customer relationship management: A literature review and classification, March 2009. Expert Systems with Applications.

[8] Heidi, Erika. (2020, April 29). How To Install Linux, Apache, MySQL, PHP (LAMP) stack on Ubuntu 20.04 | DigitalOcean. Retrieved from https://www.digitalocean.com/community/tutorials/how-toinstall-linux-apache-mysql-php-lamp-stack-on-ubuntu-2004.

[9] ISO/IEC 25010:2011. (2020). retrieved from https://www.iso.org/standard/35733.html, dated 18 May 2020.

[10] Kiss, Ágnes Orsolya. (October 19, 2016). How to integrate design into your agile process? Retrieve from https://uxstudioteam.com/ux-blog/agile-design-process/

[11] Lee, Abraham Lincoln (n.d.). Retrieve from https://ngo.diona.com/the-importance-of-good-datacollection.

[12] Navarro, Emmanuel C., Salas, Rodella F. (2020). Design and Development of NEUST - San Isidro Campus Website: Highlighting Research and Extension Services and Per Area Department. International Journal for Science and Advance Research In Technology (IJSART), (ISSN: 2395-1052), http://ijsart.com/Home/IssueDetail?id=36551, Volume 6 Issue 4, 4/30/2020, 1047 - 1053.

[13] Philippine Statistics Authority. (.n.d.). Retrieved from https://en.wikipedia.org/wiki/Philippine_Statistics_Authority

[14] Reeve, John. (13 September 2012). Planning, Tracking and Maniging Agile Web Development Sprints using Scrum and Intervals. $\quad$ Retrieved from https://www.myintervals.com/blog/2012/09/13/planningtracking-and-managing-agile-web-development-sprintsusing-scrum-and-intervals-time-and-task-management/ on May 16, 2020.

[15] Rita C. Richey, James D. Klein, Wayne A. Nelson, (January 2004) Developmental Research: Studies of Instructional Design and Development. Retrieved from
https://www.researchgate.net/publication/263963734_Devel opmental_research

[16] Richey, Rita C., Developmental Research: The Definition and Scope, 1994, https://files.eric.ed.gov/fulltext/ED373753.pdf, Information Analyses (070) --Reports--

[17] Robert J. Stimson, Roger R. Stough, Brian H. Roberts, Regional Economic Development: Analysis and Planning Strategy, Springer Science \& Business Media, 2006. Retrieved from https://books.google.com.ph/books?hl=en\&lr=\&id=UwGY2 VG4JDYC\&oi=fnd\&pg=PR6\&dq=development+analysis + \&ots=v2U2WhGilv\&sig=8JcLbIga7_bXj$\underline{8 \mathrm{aXhxkCvtPD} \text { A\&redir esc }=\mathrm{y} \# \mathrm{v}=\text { onepage } \& \mathrm{q}=\text { developmen }}$ $\mathrm{t} \% 20$ analysis $\& \mathrm{f}=$ false.

[18] Use Case Diagrams - Use Case Diagrams Online, Examples, and Tools (n.d.). Retrieved from https://www.smartdraw.com/use-casediagram/\#whatisUseCase.

Programming References:

[19] https://stackoverflow.com

[20] https://getbootstrap.com

[21] https://www.tutorialspoint.com

[22] https://material.ico

[23] https://www.startutorial.com

[24] https://www.bitbucket.org

[25] https://www.github.com 